\title{
The role of FDG PET/CT in patients treated with neoadjuvant chemotherapy for localized bone sarcomas
}

\author{
Emanuela Palmerini ${ }^{1} \cdot$ Marco Colangeli $^{2} \cdot$ Cristina Nanni $^{3} \cdot$ Stefano Fanti $^{3}$ • \\ Emanuela Marchesi ${ }^{1}$ - Anna Paioli ${ }^{1}$ - Piero Picci $^{4}$ - Silvia Cambioli ${ }^{3}$ - Davide Donati ${ }^{2}$. \\ Luca Cevolani $^{2}$ - Massimiliano De Paolis ${ }^{2}$ - Marco Gambarotti ${ }^{5,6} \cdot$ Stefano Ferrari $^{1}$
}

Received: 16 March 2016 / Accepted: 29 August 2016/Published online: 20 September 2016

(C) The Author(s) 2016. This article is published with open access at Springerlink.com

\begin{abstract}
Purpose The histological response to neoadjuvant chemotherapy is an important prognostic factor in patients with osteosarcoma (OS) and Ewing sarcoma (EWS). The aim of this study was to assess baseline primary tumour FDG uptake on $\mathrm{PET} / \mathrm{CT}$, and serum values of alkaline phosphatase (ALP) and lactate dehydrogenase (LDH), to establish whether these factors are correlated with tumour necrosis and prognosis.

Methods Patients treated between 2009 and 2014 for localized EWS and OS, who underwent FDG PET/CT as part of their staging work-up, were included. The relationships between primary tumour SUVmax at baseline (SUV1), SUVmax after induction chemotherapy (SUV2), metabolic response calculated as [(SUV1 - SUV2)/SUV1) $\times 100$, LDH and ALP and tumour response/survival were analysed. A good response (GR) was defined as tumour necrosis $>90 \%$ in patients with OS, and grade II-III Picci necrosis (persitence of microscopic foci only or no viable tumor) in patients with Ewing sarcoma.
\end{abstract}

Emanuela Palmerini

emanuela.palmerini@ior.it

1 Chemotherapy, Istituto Ortopedico Rizzoli, Via Pupilli 1, 40136 Bologna, Italy

2 Orthopaedic Surgery, Istituto Ortopedico Rizzoli, Via Pupilli 1, 40136 Bologna, Italy

3 Nuclear Medicine, Sant' Orsola Hospital, Bologna, Italy

4 Research Laboratory, Istituto Ortopedico Rizzoli, Via Pupilli 1, 40136 Bologna, Italy

5 Surgical Pathology, Istituto Ortopedico Rizzoli, Via Pupilli 1, 40136 Bologna, Italy

6 Radiology, Musculoskeletal Oncology Department, Istituto Ortopedico Rizzoli, Via Pupilli 1, 40136 Bologna, Italy
Results The study included 77 patients, 45 with EWS and 32 with OS. A good histological response was achieved in $53 \%$ of EWS patients, and $41 \%$ of OS patients. The 3-year eventfree survival (EFS) was $57 \%$ in EWS patients and $48 \%$ OS patients. The median SUV1 was 5.6 (range $0-17$ ) in EWS patients and 7.9 (range $0-24$ ) in OS patients $(p=0.006$ ). In EWS patients the GR rate was $30 \%$ in those with a high SUV1 $(\geq 6)$ and $72 \%$ in those with a lower SUV1 ( $p=$ 0.0004), and in OS patients the GR rate was $29 \%$ in those with SUV1 $\geq 6$ and $64 \%$ in those with a lower SUV1 ( $p=$ 0.05 ). In the univariate analysis the 3 -year EFS was significantly better in patients with a low ALP level (59\%) than in those with a high ALP level $(22 \%, p=0.02)$ and in patients with a low LDH level (62\%) than in those with a high LDH level (37 \%, $p=0.004)$. In EWS patients the 3-year EFS was $37 \%$ in those with a high SUV1 and $75 \%$ in those with a low SUV1 $(p=0.004)$, and in OS patients the 3-year EFS was $32 \%$ in those with a high SUV1 and $66 \%$ in those with a low SUV1 $(p=0.1)$. Histology, age and gender were not associated with survival. In the multivariate analysis, SUV1 was the only independent pretreatment prognostic factor to retain statistical significance $(p=0.017)$. SUV2 was assessed in 25 EWS patients: the median SUV2 was 1.9 (range $1-8$ ). The GR rate was $20 \%$ in patients with a high SUV2, and $67 \%$ in those with a low SUV2 $(p=0.02)$. A good metabolic response (SUV reduction of $\geq 55 \%$ ) was associated with a 3-year EFS of $80 \%$ and a poor metabolic response with a 3-year EFS of $20 \%(p=0.05)$. In the OS patients the median SUV2 was 2.7 (range $0-4.5$ ). Neither SUV2 nor the metabolic response was associated with outcome in OS patients.

Conclusion FDG PET/CT is a useful and noninvasive tool for identifying patients who are more likely to be resistant to chemotherapy. If this finding is confirmed in a larger series, SUV1, SUV2 and metabolic response could be proposed as factors for stratifying EWS patients to identify those with 
high-grade localized bone EWS who would benefit from riskadapted induction chemotherapy.

Keywords Ewing sarcoma - Osteosarcoma - PET-CT · Prognosis $\cdot$ Neo-adjuvant chemotherapy $\cdot$ SUV1

\section{Introduction}

Osteosarcoma (OS) and Ewing sarcoma (EWS) are the most frequent primitive bone tumours, with an incidence ranging from 0.2 to $0.3 / 100,000 /$ year $[1,2]$. The combination of multiagent chemotherapy, surgery and also radiotherapy in patients with EWS have dramatically improved the prognosis, with disease-free survival rates at 5 years of about $65-70 \%$ [1]. Tumour necrosis induced by neoadjuvant chemotherapy is one of the most powerful prognostic indicators of survival in patients with localized disease [3, 4]. Tumour response to neoadjuvant chemotherapy has important implications in subsequent patient management and some clinical trials have indicated that postoperative treatment should be based on histological response [5, 6]. However, pathological assessment of tumour response is only possible after resection. Therefore, an accurate and noninvasive predictive marker of response is important in designing an individualized treatment strategy in patients with localized bone sarcoma. This is particularly relevant in patients with nonextremity EWS who are undergoing radiotherapy as definitive treatment, and therefore lack histological response data $[7,8]$.

${ }^{18} \mathrm{~F}-\mathrm{FDG}$ PET/CT is now widely used in the initial diagnosis, staging and detection of recurrence in many kinds of cancer [9-14]. The role of ${ }^{18} \mathrm{~F}-\mathrm{FDG}$ PET/CT in predicting response to chemotherapy in bone sarcomas [15-22] and softtissue sarcomas [23-25] has been assessed in many studies with contradictory results $[19,26]$. However, histological heterogeneity [23, 24], limited numbers of patients included [16, 19], and especially the lack of uniform treatment [15] make the interpretation of results difficult.

The aim of the present study was to assess the prognostic role of ${ }^{18} \mathrm{~F}$-FDG uptake and its correlation with histological response to chemotherapy, in a single-institutional series of patients with EWS and OS of bone prospectively enrolled in a clinical trial (for EWS, EudraCT no. 2008-008361-35; for OS, EudraCT no. 2011-001659-36).

\section{Materials and methods}

All patients treated between April 2009 and February 2014 for localized EWS and OS enrolled in the ISG-AIEOP-EW1 and ISG/OS2 protocols, respectively and who had undergone FDG PET/CT as part of staging work-up were included.

\section{EWS and OS protocol design}

EWS patients enrolled in the ISG-AEIOP-EW1 protocol (EudraCT no. 2008-008361-35) were randomized into two arms with the same drugs delivered according to different dose intensities. In both arms patients received induction treatment followed by surgery (whenever possible) and/or radiotherapy. The maintenance treatment was given according to the response to the induction treatment (Fig. 1).OS patients enrolled in the ISG/OS2 protocol (EudraCT no. 2011-00165936) underwent induction chemotherapy with methotrexate $12 \mathrm{~g} / \mathrm{m}^{2}$ (cycles 1 and 3), and cisplatinum $120 \mathrm{mg} / \mathrm{m}^{2}$ and doxorubicin (Adriamycin) $75 \mathrm{mg} / \mathrm{m}^{2}$ (cycles 2 and 4). After surgery, patients were stratified to receive a different chemotherapy according to P-glycoprotein (ABCB1) expression and histological response. A total body FDG PET/CT scan was performed in all patients at the time of diagnosis.

\section{FDG PET/CT imaging}

Standardized uptake values (SUVmax) at baseline (SUV1) were calculated for primary tumours and recorded (Fig. 1). SUV1 is reported as median and groups were compared using Student's $t$ test. The threshold for SUV1 was identified as the median plus $1 \mathrm{SD}$ of the baseline. SUV2 was defined as the SUVmax of the primary tumour after induction chemotherapy and is reported as the median (Fig. 1). The threshold for SUV2 was identified as the median plus $1 \mathrm{SD}$.

\section{Response assessment}

\section{Metabolic response}

Metabolic responses (percentage reduction in glucose uptake) to primary chemotherapy were calculated according as:[(SUV1 SUV2)/SUV1)] $\times 100$. Metabolic responses are reported as medians and the threshold was set as the median plus 1 SD.

Each patient received $3.7 \mathrm{MBq} / \mathrm{kg}$ of ${ }^{18} \mathrm{~F}-\mathrm{FDG}$ intravenously and the PET/CT scan was performed 60-90 min after tracer administration. ${ }^{18} \mathrm{~F}$-FDG was produced in our radiopharmacy using a standard technique. PET/CT scans were carried out on a dedicated PET/CT tomograph (Discovery LS; GE Medical System, Waukesha, WI; Fig. 2). PET emission images were collected for 2 min for each bed position from the vertex of the skull to the thighs with inclusion of the upper extremities, and the CT scan was used for nonuniform attenuation correction. CT acquisition parameters were: $120 \mathrm{kV}, 80 \mathrm{~mA}, 0.8 \mathrm{~s}$ tube rotation, $3.7 \mathrm{~mm}$ slice thickness. To optimize FDG uptake in normal and neoplastic tissues, patients were asked to fast for at least $6 \mathrm{~h}$ and were encouraged to void to minimize activity in the bladder before the PET/CT scan. None of the patients had a history of diabetes. 
Fig. 1 Chemotherapy treatment schedule for the treatment of patients with localized bone tumours

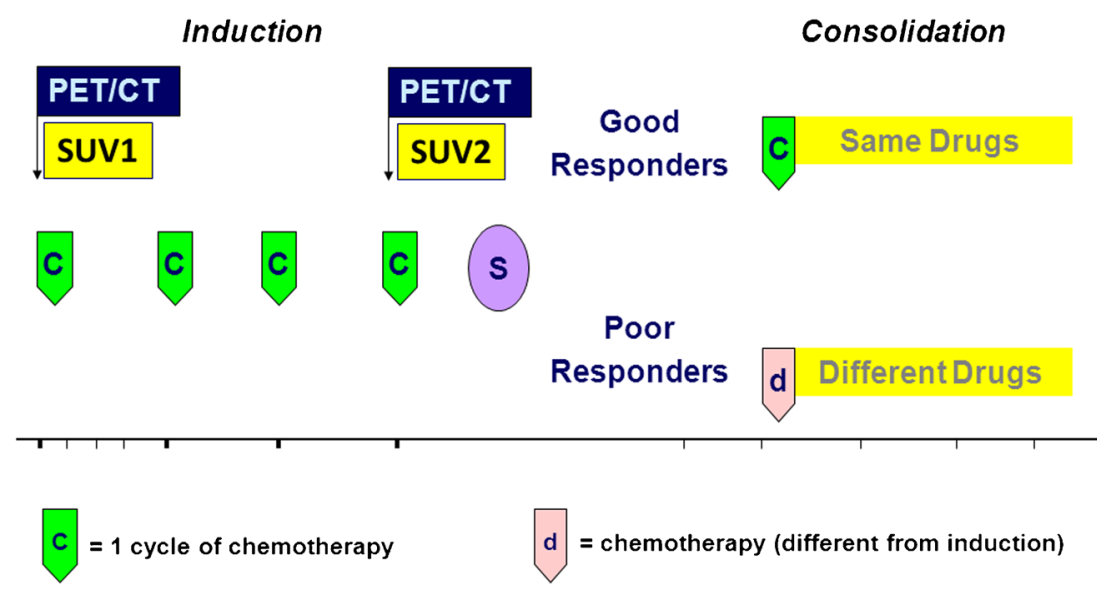

\section{Histological/radiological response}

Tumour response to chemotherapy was evaluated in all patients. In EWS patients, a histological good response (GR) was defined as grade II/III Picci necrosis in those undergoing surgery [3]. In patients undergoing radiation therapy only, as a local treatment, complete disappearance of the soft tissue component on MRI was considered a GR. In OS patients, the tumour map was analysed histologically in accordance with a previously reported method [27]. The response was considered a GR if tumour necrosis was $\geq 90 \%$.

\section{Laboratory analysis}

In all patients a chemistry panel and complete blood count tests were performed before the start of chemotherapy including alkaline phosphatase (ALP) and lactate dehydrogenase (LDH). The normal ranges for ALP at our institution are defined according to gender and age: in males aged $<12,13-17$ and $>17$ years the upper limits of the normal ranges are 300, 390 and 129 $\mathrm{U} / 1$, and in females are 300, 187 and $104 \mathrm{U} / 1$, respectively.
Fig. $2{ }^{18}$ F-FDG PET/CT images in a 37-year-old woman with a left iliac Ewing sarcoma before (a SUV1 10) and after (b SUV2 3.2) chemotherapy

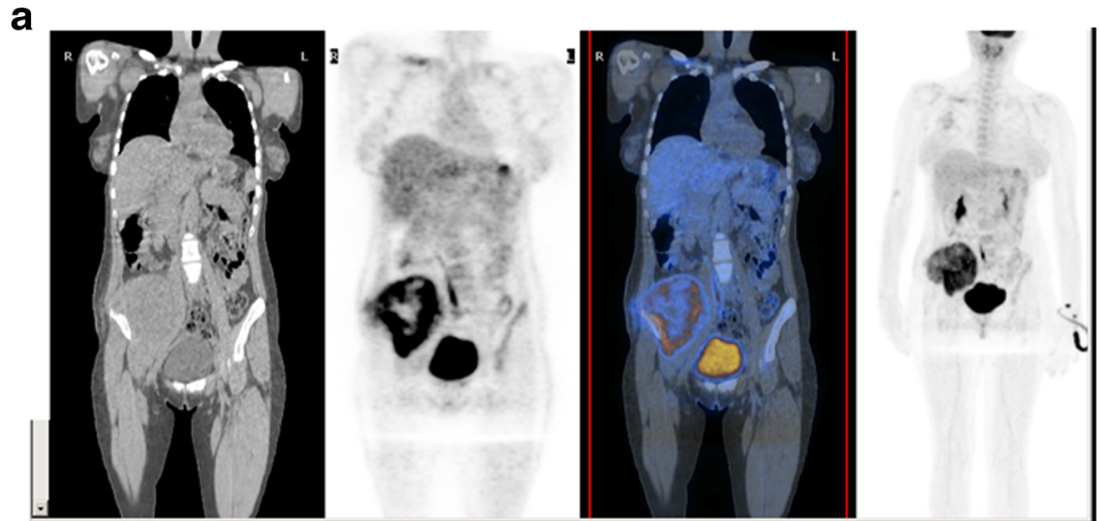

b

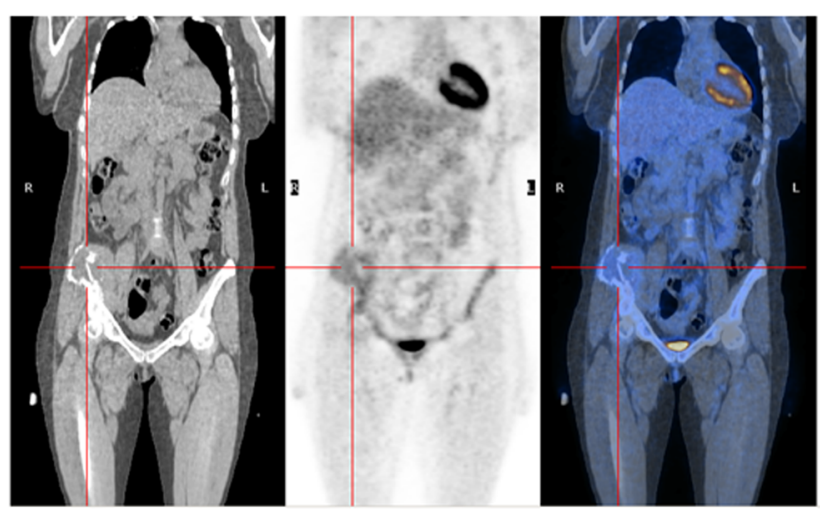

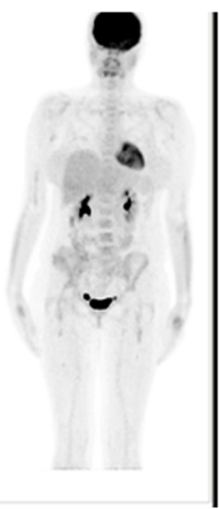




\section{Statistical analysis}

Event-free survival (EFS) was calculated from the first day of chemotherapy to recurrence (local or distant) or chemotherapy-related death, to the appearance of secondary tumours or to the last follow-up examination. Survival curves were calculated by the Kaplan-Meier method and compared using the log-rank test. In univariate analysis for EFS the following parameters were evaluated: histology (OS vs. EWS), pathological response to chemotherapy (good vs. poor), serum ALP levels (high vs. normal) and LDH levels (high vs. normal), age (adult vs. paediatric) and gender (female vs. male). The relationship between primary tumour SUV1 and SUV2 and tumour histological response/survival was also analysed.

\section{Results}

The study included 77 patients, 45 with EWS and 32 with OS. and of these 77 patients, $52(67 \%)$ were male and $25(33 \%)$ female (Table 1). The mean age of the patients at presentation was of 17 years (range $3-39$ years). The primary tumour was located in the extremities in 58 ( $75 \%$ ) of the patients (femur in 26 , tibia in 17 , fibula in 8 , humerus in 5), and in the axial skeleton in 19 patients (pelvis in 14, sacrum in 2, spine in 2, and scapula in 1). The 3 -year EFS was $35 \%$ in patients with high SUV1, and $72 \%$ in patients with low SUV1 $(p=0.001)$ overall (Fig. 3a). The median SUV1 was 6.7 (range $0-24$ ) overall. The median baseline LDH was $224 \mathrm{U} / 1$ (range 61 $841 \mathrm{U} / \mathrm{l})$, and the median ALP was $109 \mathrm{U} / 1(10-1,006 \mathrm{U} / \mathrm{l})$.

The median chemotherapy-induced tumour necrosis was $93 \%$ (range $40-100 \%$ ). Histological or radiological GR was achieved in 37 of the 77 patients $(48 \%)$ overall. The best SUV1 threshold for predicting response was 6 (Fig. 4). With the cut-off set at 6 (SUV1), the GR rate was $29 \%$ in patients with a high SUV1 $(\geq 6)$ and $69 \%$ in patients with a low SUV1 $(<6 ; p=0.0004)$ overall.

\section{Treatment, SUV1, histological response and histological outcome}

\section{Ewing sarcoma}

Of the 45 EWS patients $28(62 \%)$ received surgery and 17 $(38 \%)$ received external beam radiotherapy as local treatment. In the latter group, the decision to perform external beam radiotherapy rather than surgery was taken on a case-by-case basis by the orthopaedic surgeons, and was primarily based on age and site. In EWS patients the median SUV1 was 5.6 (range 0 -17). Histological or radiological GR was achieved in $24 /(53 \%)$ of the 45 patients, with a complete histological response in 11 patients $(24 \%)$. The GR rate was $30 \%$ in
Table 1 Clinical characteristics of the patients in the ISG-AIEOP-EW1 and ISG/OS2 studies

\begin{tabular}{|c|c|c|}
\hline & ISG-AIEOP-EW-1 & ISG/OS2 \\
\hline No. of patients & 45 & 32 \\
\hline \multicolumn{3}{|l|}{ Age (years) } \\
\hline Median & 16 & 17 \\
\hline Range & $3-37$ & $6-39$ \\
\hline \multicolumn{3}{|l|}{ Sex, $n(\%)$} \\
\hline Male & $33(73)$ & $19(59)$ \\
\hline Female & $12(27)$ & $13(41)$ \\
\hline \multicolumn{3}{|l|}{ Site, $n(\%)$} \\
\hline Extremities & $27(60)$ & $31(97)$ \\
\hline Pelvis & $14(31)$ & $0(0)$ \\
\hline Spine & $4(9)$ & $0(0)$ \\
\hline Scapula & $0(0)$ & $1(3)$ \\
\hline \multicolumn{3}{|l|}{ Alkaline phosphatase, $n(\%)$} \\
\hline Normal & $44(98)$ & $24(75)$ \\
\hline High & $1(2)$ & $8(25)$ \\
\hline \multicolumn{3}{|l|}{ Lactate dehydrogenase, $n(\%)$} \\
\hline Normal & $33(73)$ & $24(75)$ \\
\hline High & $12(27)$ & $8(25)$ \\
\hline \multicolumn{3}{|l|}{ Local therapy, $n(\%)$} \\
\hline Surgery & $28(62)$ & $32(100)$ \\
\hline External beam radiotherapy & $17(38)$ & 0 \\
\hline \multicolumn{3}{|l|}{ SUV1 } \\
\hline Median & 5.6 & 7.8 \\
\hline Range & $0-17$ & $0-24$ \\
\hline \multicolumn{3}{|l|}{ SUV2 } \\
\hline Median & 1.9 & 2.7 \\
\hline Range & $0-8$ & $0-4.5$ \\
\hline \multicolumn{3}{|c|}{ Response to induction chemotherapy, $n(\%)$} \\
\hline Good & $24(53)$ & $13(41)$ \\
\hline Poor & $21(47)$ & $19(59)$ \\
\hline
\end{tabular}

patients with a high SUV1 and $72 \%$ in those with a low SUV1 ( $p=0.004$; Fig. 5). In EWS patients the 3-year EFS was $37 \%$ in those with a high SUV1 and $75 \%$ in those with a low SUV1 ( $p=0.004$; Fig. 3b).

\section{Osteosarcoma}

All OS patients underwent surgical treatment. Their median SUV1 was 7.85 (range $0-24$ ). Histological or radiological GR was achieved in $13(41 \%)$ of the 32 patients, with a complete histological response in 3 patients $(9 \%)$. The GR rate was $20 \%$ in patients with a high SUV1 and $64 \%$ in those with a low SUV1 ( $p=0.05$; Fig. 5). In OS patients the 3-year EFS was $32 \%$ in those with a high SUV1 and $66 \%$ in those with a low SUV1 $(p=0.1$; Fig. $3 c)$. 
Fig. 3 Event-free survival (EFS) at 3 years in relation to SUV1 (low $<6$, high $\geq 6$ ) in (a) localized bone sarcoma $(O S+E W S),(\mathbf{b})$ Ewing sarcoma $(E W S)$ and (c) osteosarcoma $(O S)$

a

77 patients (OS+EWS)

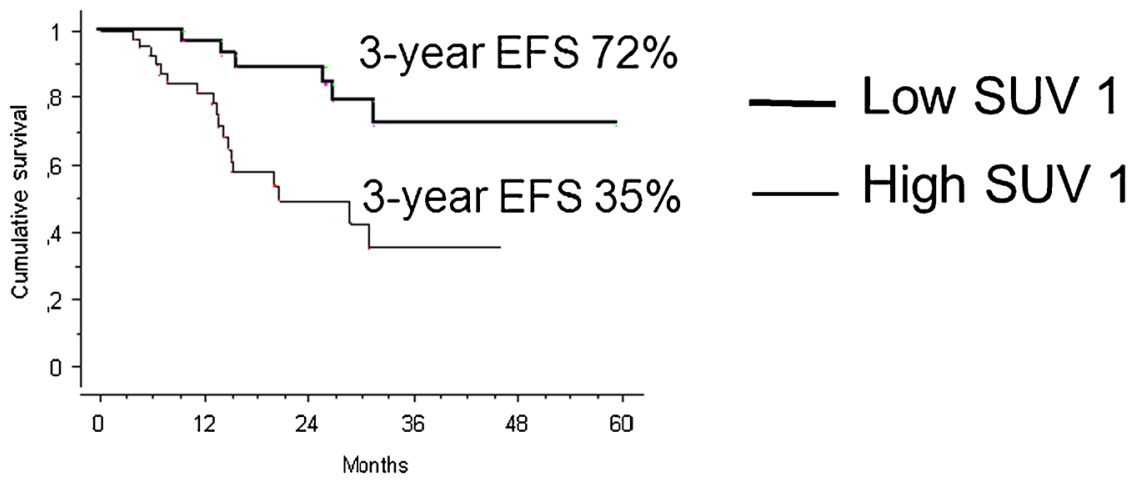

b
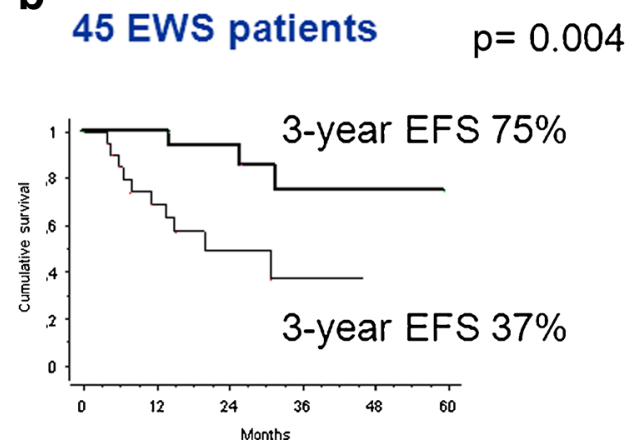

$p=0.001$

C

32 OS patients

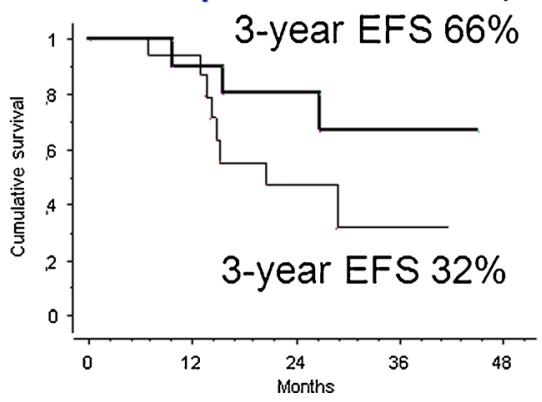

\section{Univariate and multivariate analysis for event-free survival}

The results of the univariate analysis for EFS are shown in Table 2. The 3-year EFS was significantly better in patients with a low SUV1 (72\%) than in those with a high SUV1 (36\%, $p=0.002)$, in those with a low ALP level (59\%) than in those with a high ALP level ( $22 \%, p=0.02)$, and in those with a low LDH level (62\%) than in those with a high LDH level $(37 \%, p=0.004)$. However, histology, age and gender were not associated with survival. Combining SUV1 and $\mathrm{LDH}$, four prognostic groups were identified, with worse survival in patients with a high SUV1, independent of LDH level (Table 2).

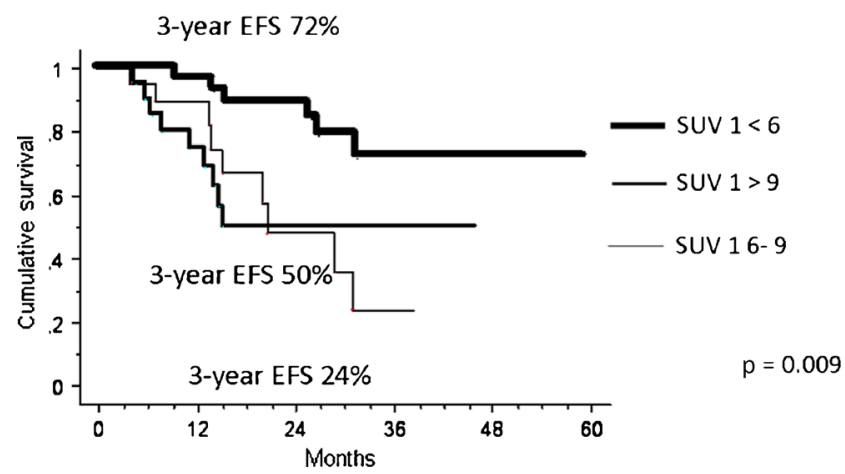

Fig. 4 Event-free survival (EFS) at 3 years in relation to SUV1 $(<6,6-$ $9,>9$ ) in localized bone sarcoma
In the multivariate analysis, SUV1 was the only independent pretreatment prognostic factor to retain statistical significance $(p=0.017$; Table 3$)$.

\section{Metabolic response: SUV2}

The results discussed in this section relate exclusively to the 25 patients with localized EWS and 12 patients with localized OS who underwent a PET scan for reassessment after induction chemotherapy.

\section{Ewing sarcoma}

The median SUV2 was 1.9 (range $1-8$ ), with a median metabolic response of $59 \%$ (range $7-99 \%$ ). The GR rate was $20 \%$ in patients with a high SUV2 $(\geq 3)$ and $67 \%$ in those with a low SUV2 $(<3 ; p=0.02)$. The 3 -year EFS was $80 \%$ in patients with a good metabolic response (reduction in SUV of $\geq 55 \%$ ) and $20 \%$ in those with a poor metabolic response (reduction in SUV of $<55 \% ; p=0.05$; Fig. 6).

\section{Osteosarcoma}

The median SUV2 was 2.7 (range $0-4.5$ ) with a median metabolic response of $48 \%$ (range $4-99 \%$ ). The GR rate was $50 \%$ in patients with a high SUV2 $(\geq 3)$ and $75 \%$ in those with a low SUV2 $(<3 ; p=0.4)$. The 3 -year EFS was $20 \%$ in patients with a good metabolic response (reduction in SUV of 
Fig. 5 Relationship between primary tumour SUVmax at baseline (SUV1) and tumour histological response

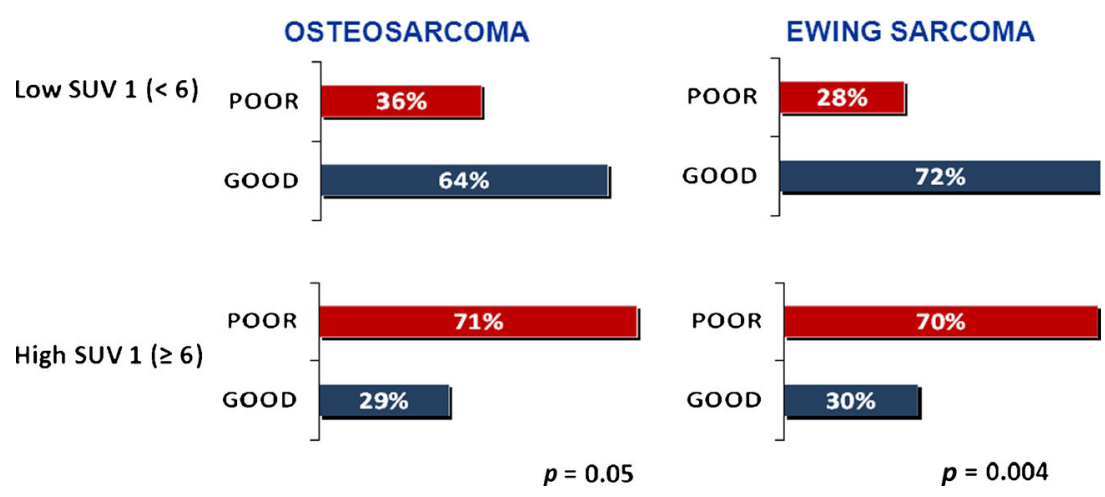

$\geq 55 \%)$ and $100 \%$ in those with a poor metabolic response (reduction in SUV of $<55 \%$; $p$ not assessable).

\section{Discussion}

A histological response to neoadjuvant chemotherapy is one of the strongest prognostic factors in patients with OS [27-29] and EWS $[3,30]$. Histological response has significant limitations, including the ability to assess it only after 10 to 15 weeks of initial chemotherapy. The current study represents the largest series of patients with bone sarcomas in

Table 2 Univariate analysis of clinical and pathological variables for event-free survival (EFS) in patients with localized bone sarcoma

\begin{tabular}{|c|c|c|c|}
\hline Variable & $\begin{array}{l}\text { Number of } \\
\text { patients }\end{array}$ & 3-year EFS (95\% CI) & $p$ value \\
\hline Overall & 77 & $57 \%(41-73 \%)$ & \\
\hline \multicolumn{4}{|l|}{ Histology } \\
\hline \multirow{2}{*}{$\begin{array}{l}\text { Ewing sarcoma } \\
\text { Osteosarcoma }\end{array}$} & 45 & $57(38-77)$ & \multirow[t]{2}{*}{0.5} \\
\hline & 32 & $48(25-71)$ & \\
\hline \multicolumn{4}{|l|}{ Age (years) } \\
\hline$\leq 18$ & 51 & $53(33-74)$ & \multirow[t]{2}{*}{0.9} \\
\hline$>18$ & 26 & $52(29-76)$ & \\
\hline \multicolumn{4}{|l|}{ Gender } \\
\hline Female & 37 & $64(41-86)$ & \multirow[t]{2}{*}{0.3} \\
\hline Male & 40 & $46(26-66)$ & \\
\hline \multicolumn{4}{|l|}{ SUV1 } \\
\hline$<6$ & 31 & $72(51-92)$ & \multirow[t]{2}{*}{0.002} \\
\hline$\geq 6$ & 46 & $36(14-57)$ & \\
\hline \multicolumn{4}{|l|}{ LDH (baseline) } \\
\hline Low & 55 & $62(44-80)$ & \multirow[t]{2}{*}{0.004} \\
\hline High & 22 & $37(13-61)$ & \\
\hline \multicolumn{4}{|l|}{ ALP (baseline) } \\
\hline Low & 68 & $59(43-75)$ & \multirow[t]{2}{*}{0.02} \\
\hline High & 9 & $22(0-57)$ & \\
\hline \multicolumn{4}{|l|}{ SUV1/LDH (baseline) } \\
\hline$<6 \quad$ LDH low & 29 & $78(59-98)$ & \multirow[t]{4}{*}{0.00007} \\
\hline LDH high & 6 & $56(7-100)$ & \\
\hline$\geq 6 \quad$ LDH low & 36 & $36(6-67)$ & \\
\hline LDH high & 16 & $34(10-50)$ & \\
\hline
\end{tabular}

which the prognostic value of pretreatment SUV1 was assessed (Table 4). This study showed an association between SUV1 and histological/radiological response in patients with OS and in those with EWS. SUV1 was also predictive of outcome in terms of EFS in patients with EWS, with a trend in patients with OS. This is in contrast with Hawkins et al. paper, founding no differences in EFS at 4-year $(63 \%$ vs. $73 \%, \mathrm{p} 0.4$ ), in a series of 34 localized OS, with a median age of 15 [31].

To our knowledge, this is the first report of an association between SUV1 and EFS in patients with EWS. Multivariate analysis confirmed SUV1 as and independent prognostic factor, and SUV1 should be take into consideration together with other well-known prognostic factors such as patient age, and tumour site and size [3,29]. The strength of this study was the homogeneity of treatment, including the duration of neoadjuvant chemotherapy, the surgical team and pathological assessment, all important determinants of EFS that could be confounding factors in assessing the predictive value of FDG PET. The concordance between a good histological response ( $>90 \%$ tumour necrosis in OS patients and Picci II/III necrosis in EWS patients) and SUV1 $(<6)$ in this study was very robust, confirming the findings in smaller series [15, 16, 32, 33], and is in contrast with the findings of a study performed in

Table 3 Multivariate analysis of clinical and pathological variables for event-free survival in patients with localized bone sarcoma

\begin{tabular}{llll}
\hline Variable & Relative risk & $95 \%$ CI & $p$ value \\
\hline $\begin{array}{l}\text { Histology } \\
\quad \text { Osteosarcoma }\end{array}$ & 1 & & \\
$\quad$ Ewing sarcoma & 1.25 & $0.50-3.11$ & 0.623 \\
SUV1 & & & \\
$\quad$ Low & 1 & $1.24-8.52$ & 0.017 \\
$\quad$ High & 3.25 & & \\
LDH & & & 0.07 \\
$\quad$ Low & 1 & $0.93-5.14$ & \\
High & 2.18 & & 0.20 \\
ALP & & & \\
Low & 1 & $0.68-6.23$ & \\
High & 2.06 & & \\
\hline
\end{tabular}


Fig. 6 Event-free survival (EFS) at 3 years according to metabolic response after induction chemotherapy in patients with localized Ewing sarcoma

\section{EWS patients $\quad p=0.05$}

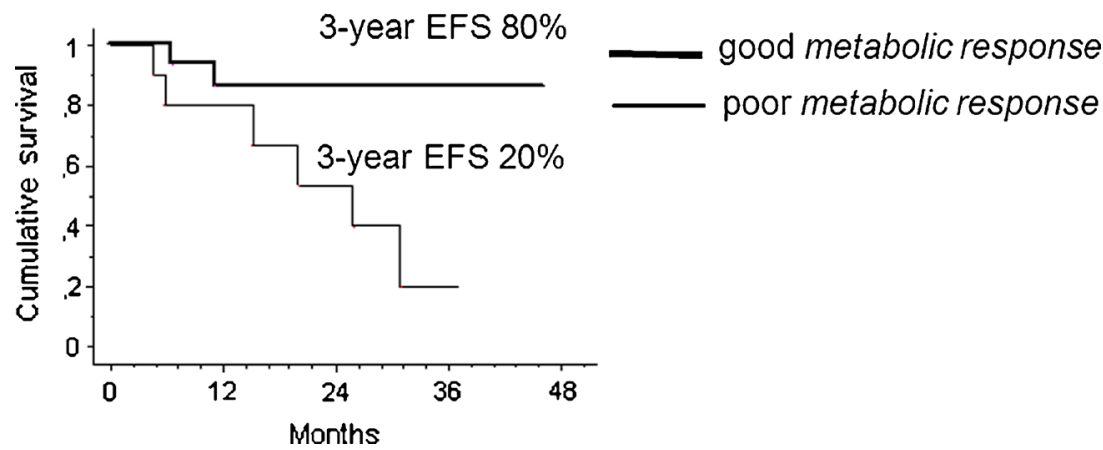

America [31]. Differences in patient characteristics (age), treatment and histological examination assessment could explain these conflicting results.

FDG PET may have several potential clinical uses. First, treating physicians may be able to identify patients who are more likely to have a less favourable histological response to neoadjuvant chemotherapy. Such patients would be candidates for more aggressive front-line chemotherapy. Nonrandomized clinical trials have suggested that augmentation of chemotherapy in response to a poor histological response can improve outcome [34, 35]. However, this observation has been refuted in other studies [36, 37], including the randomized European and American Osteosarcoma Study Group trial (EURAMOS-1), in which the hypothesis that a response-adapted therapy would provide a survival benefit was not confirmed [38].

It is possible that SUV1-adapted chemotherapy would be more useful than histological response-adapted chemotherapy, because of the ability to identify chemotherapyresistant patients from the beginning of therapy. Furthermore, combining SUV1 level with one or more already validated prognostic factors such as patients age or LDH level could eventually identify a 'prognostic score', similar to those used in other malignancies such as breast cancer. SUV2 seems exclusively useful in EWS patients. In our study SUV2 was able to predict histological response, as shown in a paediatric series [32], and might be used for example by surgeons to plan a local

Table 4 Studies on the use of FDG PET in localised bone sarcoma including outcome correlation and SUV thresholds

\begin{tabular}{|c|c|c|c|c|c|c|c|c|c|}
\hline Reference & Year & $\begin{array}{l}\text { Median age } \\
\text { (years) }\end{array}$ & $\begin{array}{l}\text { No. of } \\
\text { patients }\end{array}$ & Histology & $\begin{array}{l}\text { SUV1 } \\
\text { (median) }\end{array}$ & End-point & SUV threshold & Survival (\%) & $p$ value \\
\hline [7] & 2005 & 18.7 & $36^{\mathrm{a}}$ & Ewing sarcoma & 7.9 & 4-year PFS & $\begin{array}{l}<6 \\
\geq 6\end{array}$ & $\begin{array}{l}62 \\
52\end{array}$ & 0.47 \\
\hline [31] & 2009 & 15 & $40^{\mathrm{b}}$ & Osteosarcoma & 6.8 & 4-year PFS & $\begin{array}{l}>6 \\
\leq 6\end{array}$ & $\begin{array}{l}73 \\
63\end{array}$ & 0.41 \\
\hline [15] & 2002 & 13.3 & $\begin{array}{l}18 \\
15\end{array}$ & $\begin{array}{l}\text { Osteosarcoma } \\
\text { Ewing sarcoma }\end{array}$ & $\begin{array}{l}8.2 \\
5.3\end{array}$ & $\begin{array}{l}\mathrm{ND} \\
\mathrm{ND}\end{array}$ & & & \\
\hline [22] & 2009 & 14 & 70 & Osteosarcoma & 8 & ND & & & \\
\hline [20] & 2013 & 21 & 26 & Osteosarcoma & 9.2 & ND & & & \\
\hline [16] & 2002 & 14 & 26 & Osteosarcoma & 12.6 & 3-year EFS & 12.6 & $\begin{array}{l}90 \\
28\end{array}$ & $<0.005$ \\
\hline [25] & 1996 & $\begin{array}{l}19 \\
16\end{array}$ & $\begin{array}{l}4 \\
1\end{array}$ & $\begin{array}{l}\text { Osteosarcoma } \\
\text { Ewing sarcoma }\end{array}$ & $\begin{array}{l}5.8 \\
5.8\end{array}$ & ND & & & \\
\hline [19] & 2006 & 17.5 & 10 & Osteosarcoma & 9.1 & ND & & & \\
\hline [32] & 2016 & 12.6 & 50 & Ewing sarcoma & 5 & ND & & & \\
\hline \multirow[t]{2}{*}{ Palmerini et al. } & this study & 17 & 32 & Osteosarcoma & 7.8 & 3-year EFS & $\begin{array}{l}<6 \\
\geq 6\end{array}$ & $\begin{array}{l}66 \\
32\end{array}$ & 0.1 \\
\hline & & 16 & 45 & Ewing sarcoma & 5.6 & 3-year EFS & $\begin{array}{l}<6 \\
\geq 6\end{array}$ & $\begin{array}{l}75 \\
37\end{array}$ & 0.004 \\
\hline
\end{tabular}

EFS Event-free survival, PFS Progression-free survival, $N D$ not done

a 12 metastatic

${ }^{\mathrm{b}} 6$ metastatic 


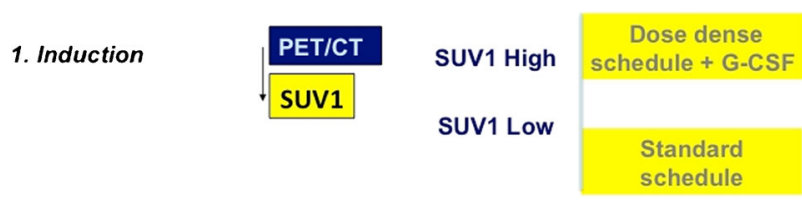

2. Consolidation
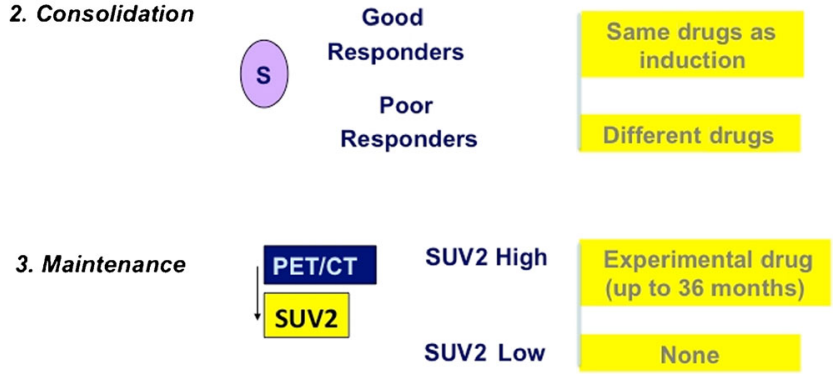

Fig. 7 Treatment algorithm for the use of FDG PET/CT in patients with localized Ewing sarcoma ( $G$-CSF granulocyte colony-stimulating factor)

treatment approach. Furthermore, a good metabolic response was associated with best survival in EWS patients (80\% 3-year EFS in patients with a reduction in SUV2 of $\geq 55 \%$, in contrast to $20 \%$ in patients with a poor metabolic response). In OS patients metabolic response did not appear to be a valid prognostic tool, in contrast by previously reported findings in children and young adults [31]. The major limitation of this subanalysis was the small sample size.

In conclusion, this is an important study on the role of PET in the management of localized bone sarcomas. The study demonstrated that an SUV1 $<6$ before neoadjuvant chemotherapy was an independent prognostic factor for EFS. The study confirmed that FDG PET imaging can complement histological response. Only in EWS patients was a good metabolic response associated with the best survival, and a treatment algorithm based on FDG PET/CT data could be proposed in patients with localized EWS (Fig. 7). Additional research should prospectively address the impact on survival of treatment modification in patients who are at greater risk of disease recurrence.

\section{Compliance with ethical standards}

Funding This work was supported by the Regione - Università Project, A. Liberati, Italian Ministry of Health - Project Alleanza contro il Cancro (ACC), an "Associazione Matteo Amitrano ONLUS" research grant, and an ESMO Congress Travel Grant.

\section{Conflict of interest None.}

Ethical approval All procedures performed in studies involving human participants were in accordance with the ethical standards of the institutional and/or national research committee and with the principles of the 1964 Declaration of Helsinki and its later amendments or comparable ethical standards.
Open Access This article is distributed under the terms of the Creative Commons Attribution 4.0 International License (http:// creativecommons.org/licenses/by/4.0/), which permits unrestricted use, distribution, and reproduction in any medium, provided you give appropriate credit to the original author(s) and the source, provide a link to the Creative Commons license, and indicate if changes were made.

\section{References}

1. ESMO/European Sarcoma Network Working Group. Bone sarcomas. ESMO clinical practice guidelines for diagnosis, treatment and follow-up. Ann Oncol. 2014;25 Suppl 3:iii113-23.

2. Meyers PA, Gorlick R. Osteosarcoma. Pediatr Clin North Am. 1997;44:973-89.

3. Picci P, Böhling T, Bacci G, Ferrari S, Sangiorgi L, Mercuri M, et al. Chemotherapy-induced tumor necrosis as a prognostic factor in localized Ewing's sarcoma of the extremities. J Clin Oncol. 1997;15(4):1553-9.

4. Davis AM, Bell RS, Goodwin PJ. Prognostic factors in osteosarcoma: a critical review. J Clin Oncol. 1994;12:423-31.

5. Ferrari S, Ruggieri P, Cefalo G, Tamburini A, Capanna R, Fagioli F, et al. Neoadjuvant chemotherapy with methotrexate, cisplatin, and doxorubicin with or without ifosfamide in nonmetastatic osteosarcoma of the extremity: an Italian Sarcoma Group trial ISG/OS-1. J Clin Oncol. 2012;17:2112-8.

6. Ferrari S, Sundby Hall K, Luksch R, Tienghi A, Wiebe T, Fagioli F, et al. Nonmetastatic Ewing family tumors: high-dose chemotherapy with stem cell rescue in poor responder patients. Results of the Italian Sarcoma Group/Scandinavian Sarcoma Group III protocol. Ann Oncol. 2011;22(5):1221-7.

7. Hawkins DS, Schuetze SM, Butrynski JE, Rajendran JG, Vernon CB, Conrad 3rd EU, et al. [18F]Fluorodeoxyglucose positron emission tomography predicts outcome for Ewing sarcoma family of tumors. J Clin Oncol. 2005;23(34):8828-34.

8. Gaspar N, Hawkins DS, Dirksen U, Lewis IJ, Ferrari S, Le Deley $\mathrm{MC}$, et al. Ewing sarcoma: current management and future approaches through collaboration. J Clin Oncol. 2015;33(27):303646.

9. Jeong YJ, Kang DY, Yoon HJ, Son HJ. Additional value of F-18 FDG PET/CT for initial staging in breast cancer with clinically negative axillary nodes. Breast Cancer Res Treat. 2014;145(1): 137-42.

10. Ozis SE, Soydal C, Akyol C, Can N, Kucuk ON, Yagcı C, et al. The role of $18 \mathrm{~F}$-fluorodeoxyglucose positron emission tomography/ computed tomography in the primary staging of rectal cancer. World J Surg Oncol. 2014;12:26.

11. Kostakoglu L, Goldsmith SJ. Fluorine-18 fluorodeoxyglucose positron emission tomography in the staging and follow-up of lymphoma: is it time to shift gears? Eur J Nucl Med. 2000;27(10):1564-78.

12. Ding Q, Cheng X, Yang L, Zhang Q, Chen J, Li T, et al. PET/CT evaluation of response to chemotherapy in non-small cell lung cancer: PET response criteria in solid tumors (PERCIST) versus response evaluation criteria in solid tumors (RECIST). J Thorac Dis. 2014;6(6):677-83.

13. Park S, Lee SJ, Chang WJ, Maeng CH, Hong JY, Choi MK, et al. Positive correlation between baseline PET or PET/CT findings and clinical parameters in multiple myeloma patients. Acta Haematol. 2014;131(4):193-9.

14. Nanni C, Zamagni E, Versari A, Chauvie S, Bianchi A, Rensi M, et al. Image interpretation criteria for FDG PET/CT in multiple myeloma: a new proposal from an Italian expert panel. IMPeTUs 
(Italian Myeloma criteria for PET USe). Eur J Nucl Med Mol Imaging. 2016;43(3):414-21.

15. Hawkins DS, Rajendran JG, Conrad 3rd EU, Bruckner JD, Eary JF. Evaluation of chemotherapy response in pediatric bone sarcomas by [F-18]-fluorodeoxy-D-glucose positron emission tomography. Cancer. 2002;94(12):3277-84.

16. Franzius C, Bielack S, Flege S, Sciuk J, Jurgens H, Schober O. Prognostic significance of $18 \mathrm{~F}-\mathrm{FDG}$ and $99 \mathrm{mTc}$-methylene diphosphonate uptake in primary osteosarcoma. J Nucl Med. 2002;43:1012-7.

17. Costelloe CM, Macapinlac HA, Madewell JE. 18F-FDG PET/CT as an indicator of progression-free and overall survival in osteosarcoma. J Nucl Med. 2009;50(3):340-7.

18. Costelloe CM, Chuang HH, Madewell JE. FDG PET/CT of primary bone tumors. AJR Am J Roentgenol. 2014;202(6):W521-31.

19. Huang TL, Liu RS, Chen TH, Chen WY, Hsu HC, Hsu YC. Comparison between F-18-FDG positron emission tomography and histology for the assessment of tumor necrosis rates in primary osteosarcoma. J Chin Med Assoc. 2006;69(8):372-6.

20. Kong CB, Byun BH, Lim I, Choi CW, Lim SM, Song WS, et al. 18F-FDG PET SUVmax as an indicator of histopathologic response after neoadjuvant chemotherapy in extremity osteosarcoma. Eur J Nucl Med Mol Imaging. 2013;40(5):728-36.

21. Caldarella C, Salsano M, Isgrò MA, Treglia G. The role of fluorine18-fluorodeoxyglucose positron emission tomography in assessing the response to neoadjuvant treatment in patients with osteosarcoma. Int J Mol Imaging. 2012;2012:870301.

22. Cheon GJ, Kim MS, Lee JA, Lee SY, Cho WH, Song WS, et al. Prediction model of chemotherapy response in osteosarcoma by 18F-FDG PET and MRI. J Nucl Med. 2009;50(9):1435-40.

23. Borbély K, Németh Z, Kásler M. Clinical application of 18F-FDG PET/CT in the treatment of sarcomas. Magy Onkol. 2014;58(1):24-31.

24. Rakheja R, Makis W, Tulbah R, Skamene S, Holcroft C, Nahal A, et al. Necrosis on FDG PET/CT correlates with prognosis and mortality in sarcomas. AJR Am J Roentgenol. 2013;201(1):170-7.

25. Jones DN, McCowage GB, Sostman HD, Brizel DM, Layfield L, Charles HC, et al. Monitoring of neoadjuvant therapy response of soft-tissue and musculoskeletal sarcoma using fluorine-18-FDG PET. J Nucl Med. 1996;37:1438-44.

26. Iagaru A, Masamed R, Chawla SP, Menendez LR, Fedenko A, Conti PS. F-18 FDG PET and PET/CT evaluation of response to chemotherapy in bone and soft tissue sarcomas. Clin Nucl Med. 2008;33(1):8-13.

27. Picci P, Bacci G, Campanacci M, Gasparini M, Pilotti S, Cerasoli S, et al. Histologic evaluation of necrosis induced by chemotherapy: regional mapping of viable and nonviable tissue. Cancer. 1985;56: $1515-21$
28. Meyers P, Schwartz C, Krailo M, Kleinerman ES, Betcher D, Bernstein ML, et al. Osteosarcoma: a randomized, prospective study of the addition of ifosfamide and/or muramyl tripeptide to cisplatin, doxorubicin, and high-dose methotrexate. J Clin Oncol. 2005;23:2004-11.

29. Bielack SS, Kempf-Bielack B, Delling G, Exner GU, Flege S, Helmke K, et al. Prognostic factors in high-grade osteosarcoma of the extremity or trunk: an analysis of 1702 patients treated on neoadjuvant Cooperative Osteosarcoma Study Group protocols. J Clin Oncol. 2002;20:776-90.

30. Palmerini E, Staals EL, Ferrari S, Bacci G. Diagnosis and prognosis for the Ewing family of tumors. Expert Opin Med Diagn. 2009;3(4):445-52.

31. Hawkins DS, Conrad 3rd EU, Butrynski JE, Schuetze SM, Eary JF. [F-18]-fluorodeoxy-D-glucose-positron emission tomography response is associated with outcome for extremity osteosarcoma in children and young adults. Cancer. 2009;115(15):3519-2.

32. Raciborska A, Bilska K, Drabko K, Michalak E, Chaber R, Pogorzała M, et al. Response to chemotherapy estimates by FDG PET is an important prognostic factor in patients with Ewing sarcoma. Transl Oncol. 2016;18(2):189-95.

33. Schulte M, Brecht-Krauss D, Werner M, Hartwig E, Sarkar MR, Keppler P, et al. Evaluation of neoadjuvant therapy response of osteogenic sarcoma using FDG PET. J Nucl Med. 1999;40:163743.

34. Bacci G, Picci P, Ferrari S, Ruggieri P, Casadei R, Tienghi A, et al. Primary chemotherapy and delayed surgery for nonmetastatic osteosarcoma of the extremities: results in 164 patients preoperatively treated with high doses of methotrexate followed by cisplatin and doxorubicin. Cancer. 1993;72:3227-38.

35. Rosen G, Marcove RC, Caparros B, Nirenberg A, Kosloff C, Huvos AG. Primary osteogenic sarcoma: the rationale for preoperative chemotherapy and delayed surgery. Cancer. 1979;43:2163-77.

36. Provisor AJ, Ettinger LJ, Nachman JB, Krailo MD, Makley JT, Yunis EJ, et al. Treatment of non-metastatic osteosarcoma of the extremity with pre- and postoperative chemotherapy, CCG-782: a report from the Children's Cancer Group. J Clin Oncol. 1997;15: $76-84$.

37. Meyers PA, Gorlick R, Heller G, Casper E, Lane J, Huvos AG, et al. Intensification of preoperative chemotherapy for osteogenic sarcoma: results of the Memorial Sloan-Kettering (T12) protocol. J Clin Oncol. 1998;16:2452-8.

38. Whelan JS, Bielack SS, Marina N, Smeland S, Jovic G, Hook JM, et al. EURAMOS-1, an international randomised study for osteosarcoma: results from pre-randomisation treatment. Ann Oncol. 2015;26(2):407-14. 